\title{
The complicated role of Nrf2 in allergy and asthma
}

Cheryl E. Rockwell ${ }^{1,2,3,4, *}$, Yining Jin ${ }^{1}$, Allison P. Boss ${ }^{1,5}$, Luca M. Kaiser ${ }^{1,6}$ and Saamera Awali ${ }^{1}$

${ }^{1}$ Department of Pharmacology and Toxicology, College of Human Medicine, Michigan State University, East Lansing, Michigan 48824, United States of America

${ }^{2}$ Institute for Integrative Toxicology, Michigan State University, East Lansing, Michigan 48824, United States of America

${ }^{3}$ Cell and Molecular Biology Program, Michigan State University, East Lansing,

Michigan 48824, United States of America

${ }^{4}$ Applied Immunology Center for Education and Research, Michigan State University, East Lansing, Michigan 48824, United States of America

${ }^{5}$ Department of Food Science and Human Nutrition, Michigan State University, East Lansing, Ml 48824, United States of America

${ }^{6}$ College of Osteopathic Medicine, Michigan State University, East Lansing, MI 48824, United States of America 


\section{Running Title Page}

Running Title: Role of Nrf2 in allergy

* Corresponding Author: Cheryl E. Rockwell, Department of Pharmacology and Toxicology, College of Human Medicine, Michigan State University, East Lansing, Michigan 48824, United States of America. Email: rockwelc@msu.edu (CER), phone: 1517-353-1251.

Text pages: 36

Tables: 2

References: 107

Word count in the Abstract: 123

Word count in the Introduction: 361

Word count in the Current Challenges and Future Directions: 415

Abbreviations: ACD: Allergic contact dermatitis, AD: Atopic dermatitis, AO: aldehyde oxidase, AREs: Antioxidant response elements, BACH1: BTB Domain And CNC Homolog 1, BALF: Bronchoalveolar lavage fluid, bZIP: basic leucine zipper, CDDO-Im: 1- [2-cyano-3-,12- dioxooleana-1,9(11)-dien-28-oyl] imidazole, CNC: Cap "n" Collar, COPD: Chronic Obstructive Pulmonary Disease, CS: cigarette smoke, CYP2E1: Cytochrome P450 Family 2 Subfamily E Member 1, Cys: cysteine, DC: dendritic cells, DDC: 2', 3'-dihydroxy-4', 6'-dime-thoxychalcone, DLG: Asp 29 -Leu Le-Gly $_{31}$, DMF: dimethyl fumarate, DNCB: 2,4-dinitrochlorobenzene, DNFB: 1-fluoro-2,4-dinitrobenzene, ECH: 
Enoyl-CoA Hydratase, ETGE: Glu79-Thr ${ }_{80}-$ Gly $_{81}-\mathrm{Gl}_{82}, \mathrm{GCLM:} \mathrm{Glutamate-Cysteine}$ Ligase Modifier Subunit, GPX1: Glutathione Peroxidase 1, GSTP1: Glutathione STransferase Pi 1, y-GCS: y-glutamyl cysteinyl synthetase, HDMs: House dust mites, HO-1: Heme Oxygenase 1, ILC2: Group 2 Innate Lymphoid Cells, Keap1: Kelch ECHassociating protein 1, KO: Knockout, L-PGDS: lipocalin-prostaglandin D synthase, Maf: musculoaponeurotic fibrosarcoma, NAT2: N-Acetyltransferase 2, Neh: Nrf2-ECH homology, NF-E2: Nuclear factor, erythroid 2, NQO1: NAD(P)H quinone-oxidoreductase-1, Nrf2: Nuclear factor, erythroid derived 2, -like 2, OVA: ovalbumin, PM: particulate matter, PMN: Polymorphonuclear neutrophils, SPRR2: Small proline-rich protein 2, UFP: Ultrafine particle, WT: Wild-type

Keywords: Nrf2; allergy; airway inflammation; asthma; atopic dermatitis; therapeutic 


\begin{abstract}
Nrf2 is a stress-activated transcription factor that is highly responsive to oxidative stress and electrophilic stimuli. Upon activation, Nrf2 upregulates a battery of cytoprotective genes meant to prevent cell death and/or damage. In many models of inflammation, Nrf2 protects against the immune response and decreases injury, including in the context of asthma and allergy. However, in some models of asthma and allergy, Nrf2 either does not play a role or can even exacerbate inflammation. In general, the reasons behind these discrepencies are not clear and the mechanisms by which Nrf2 modulates immune response are largely uncharacterized. The aim of this review is to highlight current literature assessing the role of Nrf2 in allergy and asthma to understand Nrf2 as a potential therapeutic target.
\end{abstract}

\title{
Significance Statement
}

Nrf2 is an important immune mediator that modulates numerous immune cell types in various inflammatory diseases, including allergy and asthma. There is considerable interest in Nrf2 as a drug target in inflammation, which is complicated by the complex nature of Nrf2 in the immune system. This review focuses on the role of Nrf2 in asthma and allergy, including the endogenous role of Nrf2 in regulating immune cell function and the role of Nrf2 in detoxifying xenobiotics that exacerbate these diseases. 


\section{Introduction}

Nuclear factor, erythroid derived 2, -like 2 (Nrf2: encoded by Nfe2l2) was identified as a member of the Cap " $n$ " Collar (CNC) basic leucine zipper (bZIP) transcription factor family in 1994 (Moi et al., 1994). It was first isolated from K562 cells (a human chronic myelogenous leukemia cell line) where it was found binding to the $\beta$-globin locus control region. The name Nrf2 was adopted from the nomenclature for the transcription factor, nuclear factor, erythroid derived 2, -like1 (Nrf1), which was named because of its similarities with NF-E2 (Nuclear factor, erythroid 2) (Chan et al., 1993). However, unlike NF-E2, which is essential for erythropoiesis and is neonatally lethal in mice when knocked out, Nrf2 gene function is not necessary for blood cell differentiation and homozygous Nrf2-null offspring are fertile and produce normal litter sizes (Shivdasani and Orkin, 1995; Chan et al., 1996; Williams et al., 2016). Subsequent research has demonstrated that Nrf2 forms a heterodimer with small Maf proteins and regulates the expression of Nrf2-target genes involved in oxidative stress response and drug detoxification such as $\mathrm{NAD}(\mathrm{P}) \mathrm{H}$ quinone-oxi-doreductase-1 (NQO1), y-glutamyl cysteinyl synthetase ( $\mathrm{\gamma}-\mathrm{GCS})$, heme-oxygenase-1 (HO-1) by binding to the antioxidant response elements (AREs) in the promoter regions of these genes (Itoh et al., 1997; Thimmulappa et al., 2002; Nguyen et al., 2003; Tong et al., 2006). In addition to its antioxidant and detoxification roles, Nrf2 plays a protective anti-inflammatory role in many different animal models of inflammation. While much is known about the mechanism by which Nrf2 protects against reactive toxicants and oxidative stress, the 
mechanism by which Nrf2 modulates immune cell function is not nearly as well understood. We recently published a review focused on the role of Nrf2 in autoimmunity and infectious disease (Freeborn and Rockwell, 2021). In addition, others have reviewed the role of Nrf2 in inflammation and Nrf2/NFkB crosstalk (Li et al., 2008a; Wardyn et al., 2015; Ahmed et al., 2017; Mohan and Gupta, 2018; Staurengo-Ferrari et al., 2018; Saha et al., 2020; Bhandari et al., 2021; Freeborn and Rockwell, 2021). To complement these previous reviews, the purpose of the present paper is to review what is known about the role of Nrf2 in asthma and allergy.

\section{Brief historical perspective}

\section{Structure and Regulation of Nrf2 protein}

The Nrf2 protein comprises six highly conserved Nrf2- Enoyl-CoA Hydratase(ECH) homology (Neh) domains (Neh1-6) (Ma, 2013). Each domain has a distinct function. Neh1 contains the CNC-bZIP domain, which allows Nrf2 to heterodimerize with small Mafs (MafF/G/K) and to bind to the ARE/EpRE (Satta et al., 2017). The Neh3, Neh4 and

Neh5 domains contribute to Nrf2 transactivation (Satta et al., 2017). The redoxinsensitive Neh6 degron is essential for the degradation of the Nrf2 in stressed cells (McMahon et al., 2004). In contrast, in homeostatic cells, the Glu79-Thr80-Gly81-Glu82 (ETGE) tetrapeptide motif and Asp29- Leu30-Gly 31 (DLG) motif within the redox-sensitive Neh2 domain interact with Keap1 (Kelch ECH-associating protein 1). Keap1 represses Nrf2 by associating with an ubiquitin E3 ligase which polyubiquinates the Nrf2 protein resulting in its subsequent degradation by the $26 \mathrm{~S}$ proteasome (Canning et al., 2015). However, under conditions of oxidative stress, or in the presence of electrophilic 
xenobiotics, the conformation of Keap1 is changed which disrupts the polyubiquitination and degradation of Nrf2. Subsequently, Nrf2 translocates and accumulates in the nucleus where it activates Nrf2-target genes to induce expression of antioxidant proteins, detoxification enzymes and other protective genes (Itoh et al., 2003; Kensler et al., 2007; Ma, 2013; Ahmed et al., 2017; Yamamoto et al., 2018).

The regulation of the Nrf2 signaling pathway is complex. Nrf2 stability can be enhanced through inhibition of Keap1 or disruption of the Nrf2-Keap1 interaction (Kansanen et al., 2013). Nrf2 activators, such as electrophilic compounds, can hinder the degradation of Nrf2 by modifying key cysteines of Keap1 and thereby changing the conformation of Keap1. Proteins that interact or compete with Keap1 can disrupt the Nrf2-Keap1 association, resulting in the accumulation of newly synthesized Nrf2. Nrf2 can also be regulated at transcription level. The promoter region of $\mathrm{Nfe} 212$ (the gene which encodes Nrf2) contains xenobiotic response element-like (XRE) sequences, which are the binding sites of the aryl hydrocarbon receptor (AhR) (Miao et al., 2005). AhR is a basic helix-loop-helix transcription factor regulating xenobiotic metabolism and works in close concert with the transcription factor Nrf2 (Miao et al., 2005; Yeager et al., 2009). Published studies indicate that the Nfe2l2 gene is directly upregulated by AhR activation, and conversely, Nrf2 induces AhR expression and thus triggers several downstream events of the AhR signaling cascade (Li et al., 2019). Thus, these two xenobiotic sensors induce one another. In contrast to AhR, the NF-kB p65 subunit represses the Nrf2-ARE pathway at the transcriptional level (Liu et al., 2008). Thus, Nrf2 
expression and activity are modulated by multiple other mediators in a complex network.

Beyond the classic Nrf2/Keap1-mediated activation and degradation and transcriptional regulation of Nrf2, Nrf2 can also be regulated at the post-transcriptional level. Numerous microRNA molecules can repress Nrf2 expression by sequence-specific binding, particularly in the context of cancer (Tonelli et al., 2018). miR-29-b1 and miR-144 downregulate Nrf2 expression directly within the cytoplasm (Ayers et al., 2015). In contrast, microRNA targeting Keap1, such as miR-200a and miR7, repress Keap1 expression corresponding with Nrf2 nuclear translocation and activation (Eades et al., 2011; Kabaria et al., 2015).

\section{Evidence that Nrf2 modulates the immune system: the development of autoimmunity in Nrf2-knockout (KO) mice}

Considerable evidence points to an important role for $\mathrm{Nrf2}$ in regulating the immune system. Some of the strongest and earliest indications that Nrf2 regulates immunity were in the area of autoimmunity. Between $2004-2006$, two different groups described the spontaneous development of an autoimmune disease in Nrf2-KO mice that resembled systemic lupus erythematosus. The disease was female-predominant and characterized by autoantibody production (anti-dsDNA), formation of antibody complexes in kidney and the development of glomerulonephritis that resulted in kidney injury, among other pathologies in these animals (Li et al., 2004a; Ma et al., 2006). In addition to the spontaneous development of autoimmunity, many animal models of 
autoimmune disease were found to be more severe in Nrf2-KO mice. Antibody-induced rheumatoid arthritis (RA) is exacerbated in Nrf2-null mice, with an increase in joint damage and a decrease in the expression of antioxidant genes, such as HO-1, $\mathrm{Y}$-GCS, and thioredoxin (Wruck et al., 2011). In experimental autoimmune encephalomyelitis (EAE), Nrf2-null mice develop symptoms earlier and have increased severity of clinical outcomes when compared to wild-type (WT) controls (Johnson et al., 2010; Larabee et al., 2016). Consistent with these animal studies, the Nrf2 activator dimethyl fumarate (DMF) is used clinically to treat multiple sclerosis (Tecfidera) and psoriasis (Skilarence) in humans (Bomprezzi, 2015). Furthermore, recent studies using patient samples and animal models indicate that DMF may be beneficial for the treatment for systemic sclerosis patients as well (Toyama et al., 2018; Kourakis et al., 2020). There is evidence to show that several other Nrf2 activators, such as $3 \mathrm{H}-1,2$-dithiole-3-thione, sulforaphane, dimethyl itaconate, and A-1396076, can also ameliorate autoimmunemediated inflammation in rodents under experimental conditions (Geisel et al., 2014; Kuo et al., 2016; Kuo et al., 2020; Goess et al., 2021). The therapeutic potential of Nrf2 activators in the treatment of autoimmune disease remains an active area of research that has yielded many developments over the years. We have recently written a comprehensive review of research in this area (Freeborn and Rockwell, 2021). Taken together, these studies provide strong evidence that the Nrf2 signaling pathway modulates immune cell function and paved the way for an explosion of research into the role of Nrf2 in the immune system, including in atopic diseases. The present manuscript reviews the role of Nrf2 in asthma and allergy. In an effort to keep the review focused, we have largely restricted the studies with animal models to those where a causative 
role for Nrf2 has been established (with a few exceptions for disease models with fewer studies published).

\section{Key recent advances}

The role of Nrf2 in asthma and airway allergic Inflammation

Atopic diseases, such as asthma, allergic rhinitis, skin, and food allergy are the 6th leading cause of chronic illness in the United States (ACAAI, 2021). Asthma is a condition in which airways are hyperreactive to irritants and allergens, leading to uncontrolled airway constriction and can result in hypoxia and death (Barnes, 2015). Allergic lung inflammation and asthma are lower respiratory tract disorders characterized by reversible airflow obstruction, as well as wheezing, coughing, and chest tightness upon exposure to allergens, such as dust mites, cockroaches, mold, pollen, and animal dander (Bousquet et al., 2000). Allergic rhinitis is an upper airway disorder characterized by nasal itching, sneezing, and nasal obstruction caused by inflammation of the nose upon contact of the nasal mucosa with certain allergens, such as pollen, mold, diesel fumes, and air pollutants (Pawankar et al., 2011; Varshney and Varshney, 2015; ACAAI, 2020).

Oxidative stress in airway cells has been proposed to be a contributing factor in the pathogenesis of hyperreactive airway disorders. Extensive studies, listed in Table 1, have been conducted on the role of Nrf2 in allergic airway inflammation and asthma. For instance, genetic deletion of Nrf2 in mice increased airway inflammation and hyperresponsiveness to ovalbumin (OVA) (Rangasamy et al., 2005). Specifically, the authors demonstrated elevated type 2 cytokines such as IL-4 and IL-13 in 
bronchoalveolar lavage fluid and splenocytes in Nrf2-deficient mice after OVA challenge (Rangasamy et al., 2005). This group further showed that Nrf2 is specifically cytoprotective in airway epithelial cells in this model (Sussan et al., 2015). Consistent with this, Hirai et al, showed low Nrf2 expression correlated with increased severity in human asthma patients (Hirai et al., 2019). A study by Brown et al. showed that consumption of the Nrf2 activator sulforaphane ameliorated bronchoconstriction in $60 \%$ of individuals with moderate asthma. Interestingly, sulforaphane administration was associated with a decrease in Nrf2 target gene expression in these patients. However, $20 \%$ of the patients who consumed sulforaphane experienced exacerbated bronchoconstriction, suggesting sulforaphane was not protective in all subsets (Brown et al., 2015).

Similarly, a protective role of Nrf2 has been implied in chemical-induced asthma. Chlorine gas induced airway inflammation and asthma were significantly greater at $48 \mathrm{~h}$ post exposure in Nrf2-deficient mice compared to WT (Ano et al., 2017). Other studies have directly shown the therapeutic effect of Nrf2 activation in acute allergic asthma models. Both genetic activation of Nrf2 via deletion of its suppressor protein Keap1 and pharmacological activation of Nrf2 via 2-trifluoromethyl-2'-methoxychalone improved the cytoprotective function of the airway epithelium in an OVA-induced asthmatic mouse model (Sussan et al., 2015).

To prevent asthma-induced bronchoconstriction, long-acting beta agonists and inhaled steroids are chiefly used. Steroids, such as dexamethasone, act as a local anti- 
inflammatory agent and preserve the integrity of the airway epithelium, preventing the airway irritation that leads to constriction. However, steroids can lose their effectiveness over time. Activation of Nrf2 restores steroid sensitivity in a mouse model of asthma (Sakurai et al., 2018). The protective effects of Nrf2 in these models is likely mediated by Nrf2 target genes, rather than Nrf2 itself. Aldehyde oxidase (AO) is a well-described target gene of Nrf2 and is instrumental in the formation of tight junctions and adherent junctions in airway epithelium (Shintani et al., 2015). Genetic ablation of Nrf2 in cell lines led to decreased signaling via the AO pathway (Shintani et al., 2015). Overall, the evidence points to a protective role for Nrf2 in this model of asthma, which is likely mediated at least in part by maintaining the integrity of the airway epithelial barrier.

House dust mites (HDMs) are some of the most common perennial sources of allergens that induce asthma and allergic airway inflammation. Investigators have shown that exposure to house dust mites decreases Nrf2 levels, suggesting that antioxidant and anti-inflammatory pathways are inhibited, which may contribute to the dysregulation of sinonasal epithelial cell barrier function and the development of asthma (London et al., 2017). Nrf2 deficiency has also been shown to exacerbate the response of lung dendritic cells to ragweed extract. Specifically, Nrf2-deficient lung dendritic cells cultured in vitro showed greater induction of TNF $\alpha$ and IL-6 in response to ragweed extract (Rangasamy et al., 2010). OVA is another major allergen that induces allergic reactions, particularly in experimental animal models of allergy and asthma. Several studies have shown that OVA induces several hallmarks of allergic reactions, including sinonasal 
inflammation and most prominently, asthma (Rangasamy et al., 2005; Sussan et al., 2015).

Nrf2 deficiency is associated with mucus cell hyperplasia and eosinophilic lung infiltration in a murine OVA-induced asthma model. In these studies, bronchoalveolar lavage fluid (BALF) and splenocytes of Nrf2-deficient mice showed increased expression of IL-4 and IL-13 after OVA exposure (Rangasamy et al., 2005). Other studies have examined the role of Nrf2 in the airway epithelium after sensitization to OVA, in which they demonstrated that genetic and pharmacological Nrf2 activation suppressed asthma (Sussan et al., 2015). The suppression of OVA-induced asthma by Nrf2 was associated with increased expression of the Nrf2 target gene Nqo1 and a significant decrease in infiltrating neutrophils and lymphocytes. The secretion of cytokines like IL-4 and IL-13 in BALF was also decreased (Sussan et al., 2015). In contrast to these studies, a study by Seumois et al. in asthmatic and non-asthmatic individuals suggests Nrf2 is a strong positive determinant of Th2 differentiation in CD4 T cells in humans (Seumois et al., 2014). The data show significant enrichment of Nrf2 binding sites in Th2-specific enhancers. Consistent with this, our group has shown that activation of Nrf2 promotes Th2 differentiation of isolated murine CD4 T cells (Rockwell et al., 2012).

Epidemiological data have shown that there is a link between certain genetic polymorphisms in the NAT2, GSTP and Nfe2I2 genes and the occurrence of asthma in children if they are exposed to acetaminophen. They also reported an increase in serum 
eosinophils when children with a specific Nrf2 polymorphism were taking acetaminophen (Kang et al., 2013). However, it is not clear whether the impact of the Nrf2 polymorphism in this study is due to effects on immune cell function, detoxification of acetaminophen or some combination of these.

There has been interest in Nrf2 as a therapeutic target for chronic respiratory illnesses, including asthma (Wang et al., 2018). For example, targeted activation of Nrf2 in female mice suppresses allergic lung inflammation and alleviates OVA-induced asthma (Nagashima et al., 2019). Nrf2 activation decreases type 2 innate lymphoid cells (ILC2s), which release major allergic airway inflammation-inducing cytokines, IL-4, and IL-13 (Nagashima et al., 2019). Recently, it has been shown that Nrf2 activation by alpha lipoic acid also suppressed cytokines TNF- $\alpha$ and IL-6, which are associated with non-Th2-mediated airway inflammation (Van Nguyen et al., 2020).

\section{Nrf2, air pollution and asthma/allergy}

Air pollutants and diesel fumes are among the common causes of allergic rhinitis (Li et

al., 2020; Jung et al., 2021). Air pollutants, such as carbon monoxide, nitrogen dioxide, lead, ozone, and other particulate matter (PM), contribute to oxidative stress and inflammation in rhinitis (Lodovici and Bigagli, 2011; Pardo et al., 2020). Diesel fumes are one of the major contributors to air pollution, consisting of particulate matter composed of metals and polycyclic aromatic hydrocarbons. These diesel-derived particles have an aerodynamic diameter of $2.5 \mu \mathrm{m}$ or smaller $\left(\mathrm{PM}_{2.5}\right)$, allowing them to effortlessly penetrate the lungs. Studies have shown that exposure to $\mathrm{PM}_{2.5}$ induces 
oxidative stress by increasing cellular reactive oxygen species and inflammation, as marked by increased IL-8 expression (Buttrick et al., 2018). Studies have also indicated that exposure to $\mathrm{PM}_{2.5}$ from biodiesel results in increased inflammation marked by an increase in macrophage-derived TNF- $\alpha$ expression, as well as increased expression of Nrf2 and HO-1 proteins, suggesting that $\mathrm{PM}_{2.5}$ from biodiesel may stimulate the activation of Nrf2/HO-1 pathways (Cattani-Cavalieri et al., 2019). Exposure to $\mathrm{PM}_{2.5}$ from biodiesel increased expression of p-NF-kB, which stimulates pro-inflammatory cytokines, such as TNF- $\alpha$ (Cattani-Cavalieri et al., 2019). Similarly, diesel exhaust particles (DEP) have also been shown to activate Nrf2 in macrophage and bronchial epithelial cell lines (Li et al., 2004b). Furthermore, exposure to DEP or exposure to DEP in combination with OVA sensitization resulted in increased airway hyperresponsiveness and greater immune cell counts and cytokine levels in bronchial alveolar lavage fluid from Nrf2-KO mice, compared to WT mice (Li et al., 2008b; Li et al., 2010). Studies with ultrafine particles (UFP) indicate that adoptive transfer of Nrf2deficient dendritic cells treated with UFP and OVA into WT mice resulted in greater immune cell infiltrate, OVA-IgG 1 and IL-13 in the BALF following in vivo OVA sensitization compared to mice receiving similarly-treated WT dendritic cells ( $\mathrm{Li}$ et al., 2013). Taken together, these studies indicate that particulate matter can activate Nrf2 in the lung, which can have a protective effect in these models.

While most studies indicate that Nrf2-deficiency results in worsened oxidative stress, other studies show that Nrf2 may also contribute to injury or have no effect under certain conditions (Fig. 1). A recent study using a real-ambient air exposure system 
demonstrated that chronic exposure to real ambient air containing high levels of $\mathrm{PM}_{2.5}$ caused an increase in inflammatory infiltrate, oxidative stress and lung injury in WT, but not Nrf2-null, mice (Ding et al., 2021). The authors hypothesize that the diminished inflammation and damage observed in the Nrf2-KO mice may be due to decreased expression of CYP2E1, which they postulate produces a toxic metabolite of $\mathrm{PM}_{2.5}$. Further, they assert that induction of protective phase II enzymes is not sustained with long-term Nrf2 activation in their system. The diminished injury by chronic PM2.5 exposure in Nrf2-KO mice was corroborated in another study where it was associated with increased p62 expression and impaired intrinsic autophagy (Jiang et al., 2021). Collectively, these studies indicate that Nrf2 may contribute to lung injury resulting from chronic exposure to particulate matter under certain circumstances.

\section{Nrf2 and atopic dermatitis}

Atopic dermatitis (AD), also known as atopic eczema, is the most common inflammatory skin disease that is characterized as persistent eczematous lesions, itch, and discomfort. The pathophysiology of $A D$ involves both genetics and environmental factors which can cause epidermal barrier abnormalities and inflammation of the skin from T cells (Weidinger et al., 2018).

Many studies have identified compounds with anti-inflammatory properties in both in vitro and in vivo models of $\mathrm{AD}$ with evidence for activation of Nrf2, however it is important to note that a causative role for Nrf2 has not yet been established in most of these studies (Table 2). Specifically, studies have shown sulforaphane, saponins 
derived from Platycodon grandiflorum, quercetin, macakurzin-C derivative and a chrysin derivative all have protective effects in animal models of atopic dermatitis with data suggesting these effects correlate with Nrf2 activation (Wu et al., 2019). (Choi et al., 2014) (Karuppagounder et al., 2015)(Akram et al., 2016; Yu et al., 2019). Additional studies will be needed to identify the role of Nrf2 in these effects.

Whereas most of the evidence for a role for Nrf2 in AD comes from studies utilizing Nrf2 activators, there has been at least one study that employed Nrf2-knockout mice. Ogawa et al. demonstrated that expression of Nrf2 is required for the development of atopy in experimental AD induced by chronic TNCB treatment. Specifically, the authors showed decreased ear thickness and diminished infiltration of a number of effector cells, including mast cells, basophils and CD4 T cells in Nrf2-null mice. These effects correlated with a marked decrease in the expression of type 2 cytokines and serum IgE levels. Overall, this study suggests a role for Nrf2 in promoting type 2 immune response, inflammation and atopy in AD (Ogawa et al., 2020b).

\section{The role of Nrf2 in contact dermatitis}

Allergic contact dermatitis $(C D)$ is one on the most common skin allergies in western countries with allergens differing based on an individual's environment and personal habits (Thyssen et al., 2007). ACD is a T cell-mediated response induced by epicutaneous sensitization with an allergen that results in immunologic memory and increased inflammation at the site of re-exposure to the allergen (Vocanson et al., 
2009). In contrast to atopic dermatitis, contact dermatitis is not typically associated with a pronounced type 2 immune response.

Nrf2 is thought to play a protective role in CD through the upregulation of antioxidant and cytoprotective genes (Ma, 2013). Numerous studies have reported contact sensitizers to induce the Nrf2 pathway and they are listed in Table 2. CD34-derived dendritic cells (DC) and the THP-1 myeloid cell line were treated with various sensitizers and found an increased expression of HO-1 and NQO1 mRNA was observed.

Additionally, Nrf2 protein accumulation was found only in cells treated with chemical sensitizers (Ade et al., 2009). In keratinocytes, the antioxidant gene, HO-1, was significantly upregulated when exposed to contact sensitizers (Vandebriel et al., 2010). Others have found activation of Nrf2 to alleviate contact dermatitis through several compounds such as melatonin, JNJ7777120 (histamine H4 receptor antagonist), 2',3'dihydroxy-4',6'-dime-thoxychalcone and 6-shogaol (active compound of ginger) (Park et al., 2016; Shen et al., 2017; Mohamed et al., 2018; Takada-Takatori et al., 2019). Although these studies suggest a potential protective effect of Nrf2 activators on allergic contact dermatitis, further studies with Nrf2-deficient models are needed to identify the role of Nrf2 in these effects.

To specifically address the role of Nrf2 in CD, a study was performed using WT and Nrf2-deficient mice. These mice were sensitized using the strong contact sensitizer DNCB that resulted in a significant increase in ear swelling in Nrf2-deficient mice compared to WT mice, suggesting Nrf2 mitigates inflammation in this model (El Ali et 
al., 2013). Additionally, when mice were treated with low concentrations of DNCB, inflammation was solely observed in Nrf2-deficient mice, further supporting the idea that Nrf2 protects against CD. The protective effect of Nrf2 was not limited to DNCB as several other chemical sensitizers also increased lymphocyte proliferation in Nrf2deficient mice compared to WT mice (El Ali et al., 2013).

However, activation of Nrf2 is not protective against every contact sensitizer. Topical application of 1-fluoro-2,4-dinitrobenzene (DNFB), an immunogenic hapten, was found to elicit an antioxidant response through the expression of Nrf2 downstream targets. However, in Nrf2-deficient mice, contact hypersensitivity was not developed due to a compromised epidermal innate immune response as demonstrated by a decrease in IL$1 \alpha$ and keratinocyte-intrinsic factor, which is necessary for the development of immune memory (Ogawa et al., 2020b). Furthermore, clinical relevance of Nrf2 involvement in ACD was also assessed in this study through analysis of patients with various congenital disorders that resemble allergic contact dermatitis. Increased expression of Nrf2 and its target gene, small proline-rich protein 2, were found in the epidermis of patients with Netherton syndrome and peeling skin syndrome as compared to healthy controls. Nrf2 has also been shown to play a role in maintaining contact hypersensitivity response in aging mice. Aging is associated with diminished Th1-mediated responses, including contact hypersensitivity. The decline in the contact hypersensitivity in aged mice was more pronounced in Nrf2-deficient mice and less pronounced with treatment the Nrf2 activator, sulforaphane (Kim et al., 2008). Overall, these studies suggest that 
Nrf2 plays a contributing or causative role in the development of contact dermatitis in some instances.

Polymorphonuclear neutrophils (PMN) are involved in hapten-induced inflammation during sensitization through the activation of DC (Weber et al., 2015). Nrf2 implication in PMN recruitment to DNCB-sensitized skin in WT and Nrf2-deficient mice was reported by Helou's group. They found Nrf2 plays an important role in controlling PMN recruitment to the skin, which was demonstrated by an increase in Ly6G/C+ cells in skin of Nrf2-deficient mice following sensitization with DNCB (Helou et al., 2019).

Additionally, antioxidant genes, such as $\mathrm{HO}-1, \mathrm{GCLC}$, and NQO1, were upregulated in WT mice compared to Nrf2-deficient mice sensitized with DNCB. Notably, they discovered an upregulation in the efferocytosis receptor CD36 on macrophages in the skin of sensitized WT mice, which was not observed in Nrf2-deficient mice. Overall, this study indicates that Nrf2 regulates neutrophil recruitment during the sensitization phase in this model of contact dermatitis.

A proteomics study was performed to assess potential biomarkers of activated DC by contact allergens, such as DNCB, cinnamaldehyde (CA), and nickel (II) sulfate. Bone marrow derived dendritic cells (BMDCs) from WT and Nrf2-deficient mice were used to determine the role of Nrf2. Several proteins, specifically stress response proteins such as GCLM and HO-1, were upregulated in WT cells treated with CA and DNCB. Conversely, in Nrf2-deficient BMDCs, many of the proteins were not induced, 
suggesting Nrf2-dependent regulation (Mussotter et al., 2016). Taken together, the data from this study suggests an important role for Nrf2 in the induction of antioxidant genes by contact allergens in dendritic cells.

\section{Current Challenges, Knowledge Gaps and Future Directions}

Based on studies dating back to the 2010s, there has been interest in developing Nrf2 activators for the treatment of allergic airway disease and skin allergy. However, the available therapeutic agents for this mechanism are limited in their practicality. Some of these therapeutic agents have related risks and are shown to have low efficacy and bioavailability (Egbujor et al., 2021). One of the challenges of these therapeutic agents is the lack of accurate and appropriate pharmacokinetic and pharmacodynamic reports, as well as safety profiles for administration.

Currently, there are several FDA-approved Nrf2 activators for clinical use. Dimethyl fumarate (Tecfidera) is approved for relapsing-remitting multiple sclerosis and internationally as Fumaderm for psoriatic arthritis. Recently, monomethyl fumarate (Bafiertam) and diroximel fumarate (Vumerity) have been approved for relapsingremitting multiple sclerosis (Hoogendoorn et al., 2021). These drugs have also been tested in in vitro studies which indicate that they induce Nrf2 target genes and would potentially have an antioxidant effect. Likewise, these drugs have been shown to ameliorate the symptoms of other chronic diseases, such as . diabetes, chronic kidney disease, asthma, and dermatitis (Seidel and Roth, 2013; Hu et al., 2018; Zhao and Wen, 2018; Ogawa et al., 2020a). 
One of the major challenges in Nrf2 drug development is the lack of specificity of Nrf2 activators reacting with protein thiol targets. Most Nrf2 activators that have been approved or are under clinical development aim to react with Cys 151 of the N-terminal domain of Keap1. However, these Nrf2 activators have off-target effects and accompanied toxicity due to covalent and indiscriminate alkylation of thiol groups on other proteins (Gazaryan and Thomas, 2016; Robledinos-Anton et al., 2019). In addition, the use of these drugs is limited by the short half-life (Hoogendoorn et al., 2021). Some synthetic drug candidates, such as fumaric acid esters, sulforaphane, and nitro fatty acids have been considered as therapeutic agents and tested in clinical trials, however they present inconsistent effects related to poor absorption, metabolism, and excretion (Egbujor et al., 2021). In addition to the covalent alkylation to thiol groups of Keap1, Nrf2 activation through a non-covalent inhibition of the Nrf2-Keap1 interaction is also being considered for therapeutical use (Satoh and Lipton, 2017).

Nevertheless, there are ongoing clinical trials studying the pharmacokinetics of synthetic and naturally derived Nrf2 activators and inhibitors (Robledinos-Anton et al., 2019). Future work should be directed towards finding compounds or pro-drugs that contain a more specific reaction to key thiol groups of Keap1 to avoid systemic side effects with a good pharmacokinetic/pharmacodynamic profile. 


\section{Authorship Contributions}

Wrote or contributed to the writing of the manuscript: Yining Jin, Allison P. Boss, Luca M. Kaiser, Saamera Awali, Cheryl E. Rockwell. 


\section{References}

ACAAI (2020) Hay Fever (Rhinitis) | Symptoms \& Treatment | ACAAI Public Website. ACAAI (2021) Allergy Facts.

Ade N, Leon F, Pallardy M, Peiffer JL, Kerdine-Romer S, Tissier MH, Bonnet PA, Fabre I, and Ourlin JC (2009) HMOX1 and NQO1 genes are upregulated in response to contact sensitizers in dendritic cells and THP-1 cell line: role of the Keap1/Nrf2 pathway. Toxicol Sci 107:451-460.

Ahmed SM, Luo L, Namani A, Wang XJ, and Tang X (2017) Nrf2 signaling pathway: Pivotal roles in inflammation. Biochim Biophys Acta Mol Basis Dis 1863:585-597.

Akram M, Shin I, Kim KA, Noh D, Baek SH, Chang SY, Kim H, and Bae ON (2016) A newly synthesized macakurzin $\mathrm{C}$-derivative attenuates acute and chronic skin inflammation: The Nrf2/heme oxygenase signaling as a potential target. Toxicol Appl Pharmacol 307:62-71.

Ano S, Panariti A, Allard B, O'Sullivan M, McGovern TK, Hamamoto Y, Ishii Y, Yamamoto M, Powell WS, and Martin JG (2017) Inflammation and airway hyperresponsiveness after chlorine exposure are prolonged by Nrf2 deficiency in mice. Free Radic Biol Med 102:115.

Ayers D, Baron B, and Hunter T (2015) miRNA Influences in NRF2 Pathway Interactions within Cancer Models. J Nucleic Acids 2015:143636.

Barnes PJ (2015) Asthma / Harrison's Principles of Internal Medicine, 20e. McGraw Hill Education Medical, New York.

Bhandari R, Khanna G, Kaushik D, and Kuhad A (2021) Divulging the Intricacies of Crosstalk Between NF-Kb and Nrf2-Keap1 Pathway in Neurological Complications of COVID-19. Mol Neurobiol 58:3347-3361.

Bomprezzi R (2015) Dimethyl fumarate in the treatment of relapsing-remitting multiple sclerosis: an overview. Ther Adv Neurol Disord 8:20-30.

Bousquet J, Jeffery PK, Busse WW, Johnson M, and Vignola AM (2000) Asthma. From bronchoconstriction to airways inflammation and remodeling. Am J Respir Crit Care Med 161:1720-1745.

Brown RH, Reynolds C, Brooker A, Talalay P, and Fahey JW (2015) Sulforaphane improves the bronchoprotective response in asthmatics through Nrf2-mediated gene pathways. Respir Res 16:106.

Buttrick TS, Wang W, Yung C, Trieu KG, Patel K, Khoury SJ, Ai X, and Elyaman W (2018) Foxo1 Promotes Th9 Cell Differentiation and Airway Allergy. Sci Rep 8:818.

Canning P, Sorrell FJ, and Bullock AN (2015) Structural basis of Keap1 interactions with Nrf2. Free Radic Biol Med 88:101-107.

Cattani-Cavalieri I, Valenca SS, Lanzetti M, Carvalho GMC, Zin WA, Monte-Alto-Costa A, Porto LC, and Romana-Souza B (2019) Acute Exposure to Diesel-Biodiesel Particulate Matter Promotes Murine Lung Oxidative Stress by Nrf2/HO-1 and Inflammation Through the NF-kB/TNF-alpha Pathways. Inflammation 42:526-537.

Chan JY, Han XL, and Kan YW (1993) Cloning of Nrf1, an NF-E2-related transcription factor, by genetic selection in yeast. Proc Natl Acad Sci U S A 90:11371-11375. 
Chan K, Lu R, Chang JC, and Kan YW (1996) NRF2, a member of the NFE2 family of transcription factors, is not essential for murine erythropoiesis, growth, and development. Proc Natl Acad Sci U S A 93:13943-13948.

Choi JH, Jin SW, Han EH, Park BH, Kim HG, Khanal T, Hwang YP, Do MT, Lee HS, Chung YC, Kim HS, Jeong TC, and Jeong HG (2014) Platycodon grandiflorum root-derived saponins attenuate atopic dermatitis-like skin lesions via suppression of NF-KB and STAT1 and activation of Nrf2/ARE-mediated heme oxygenase-1. Phytomedicine 21:1053-1061.

Ding $\mathrm{H}$, Jiang $\mathrm{M}$, Li D, Zhao Y, Yu D, Zhang R, Chen W, Pi J, Chen R, Cui L, Zheng Y, and Piao J (2021) Effects of Real-Ambient PM2.5 Exposure on Lung Damage Modulated by Nrf2(-/). Front Pharmacol 12:662664.

Eades G, Yang M, Yao Y, Zhang Y, and Zhou Q (2011) miR-200a regulates Nrf2 activation by targeting Keap1 mRNA in breast cancer cells. J Biol Chem 286:40725-40733.

Egbujor MC, Saha S, Buttari B, Profumo E, and Saso L (2021) Activation of Nrf2 signaling pathway by natural and synthetic chalcones: a therapeutic road map for oxidative stress. Expert Rev Clin Pharmacol 14:465-480.

El Ali Z, Gerbeix C, Hemon P, Esser PR, Martin SF, Pallardy M, and Kerdine-Romer S (2013) Allergic skin inflammation induced by chemical sensitizers is controlled by the transcription factor Nrf2. Toxicol Sci 134:39-48.

Freeborn RA and Rockwell CE (2021) The role of Nrf2 in autoimmunity and infectious disease: Therapeutic possibilities. Adv Pharmacol 91:61-110.

Gazaryan IG and Thomas B (2016) The status of Nrf2-based therapeutics: current perspectives and future prospects. Neural Regen Res 11:1708-1711.

Geisel J, Bruck J, Glocova I, Dengler K, Sinnberg T, Rothfuss O, Walter M, Schulze-Osthoff K, Rocken M, and Ghoreschi K (2014) Sulforaphane protects from T cell-mediated autoimmune disease by inhibition of IL-23 and IL-12 in dendritic cells. J Immunol 192:3530-3539.

Goess C, Terrillon S, Mayo M, Bousquet P, Wallace C, Hart M, Mathieu S, Twomey R, DonnellyRoberts D, Namovic M, Jung P, Hu M, Richardson P, Esbenshade T, and Cuff CA (2021) NRF2 activator A-1396076 ameliorates inflammation in autoimmune disease models by inhibiting antigen dependent T cell activation. J Transl Autoimmun 4:100079.

Helou DG, Noel B, Gaudin F, Groux H, El Ali Z, Pallardy M, Chollet-Martin S, and Kerdine-Romer $S$ (2019) Cutting Edge: Nrf2 Regulates Neutrophil Recruitment and Accumulation in Skin during Contact Hypersensitivity. J Immunol 202:2189-2194.

Hirai K, Shirai T, Rachi Y, Uehara S, Ueda M, Nakatani E, and Itoh K (2019) Impact of Gene Expression Associated with Glucocorticoid-Induced Transcript 1 (GLCCI1) on Severe Asthma and Future Exacerbation. Biol Pharm Bull 42:1746-1752.

Hoogendoorn A, Avery TD, Li J, Bursill C, Abell A, and Grace PM (2021) Emerging Therapeutic Applications for Fumarates. Trends Pharmacol Sci 42:239-254.

Hu X, Rajesh M, Zhang J, Zhou S, Wang S, Sun J, Tan Y, Zheng Y, and Cai L (2018) Protection by dimethyl fumarate against diabetic cardiomyopathy in type 1 diabetic mice likely via activation of nuclear factor erythroid-2 related factor 2. Toxicol Lett 287:131-141.

Itoh K, Chiba T, Takahashi S, Ishii T, Igarashi K, Katoh Y, Oyake T, Hayashi N, Satoh K, Hatayama I, Yamamoto M, and Nabeshima Yi (1997) An Nrf2/small Maf heterodimer mediates the 
induction of phase II detoxifying enzyme genes through antioxidant response elements. Biochemical and Biophysical Research Communications 236:313-322.

Itoh K, Wakabayashi N, Katoh Y, Ishii T, O'Connor T, and Yamamoto M (2003) Keap1 regulates both cytoplasmic-nuclear shuttling and degradation of $\mathrm{Nrf2}$ in response to electrophiles. Genes Cells 8:379-391.

Jiang M, Li D, Piao J, Li Y, Chen L, Li J, Yu D, Pi J, Zhang R, Chen R, Chen W, and Zheng Y (2021) Nrf2 modulated the restriction of lung function via impairment of intrinsic autophagy upon real-ambient PM2.5 exposure. J Hazard Mater 408:124903.

Johnson DA, Amirahmadi S, Ward C, Fabry Z, and Johnson JA (2010) The absence of the proantioxidant transcription factor $\mathrm{Nrf2}$ exacerbates experimental autoimmune encephalomyelitis. Toxicol Sci 114:237-246.

Jung HJ, Ko YK, Shim WS, Kim HJ, Kim DY, Rhee CS, Park MK, and Han DH (2021) Diesel exhaust particles increase nasal symptoms and IL-17A in house dust mite-induced allergic mice. Sci Rep 11:16300.

Kabaria S, Choi DC, Chaudhuri AD, Jain MR, Li H, and Junn E (2015) MicroRNA-7 activates Nrf2 pathway by targeting Keap1 expression. Free Radic Biol Med 89:548-556.

Kang SH, Jung YH, Kim HY, Seo JH, Lee JY, Kwon JW, Kim BJ, Kim HB, Lee SY, Jang GC, Song DJ, Kim WK, Shim JY, Kim JH, Kang MJ, Yu HS, Yu J, and Hong SJ (2013) Effect of paracetamol use on the modification of the development of asthma by reactive oxygen species genes. Ann Allergy Asthma Immunol 110:364-369 e361.

Kansanen E, Kuosmanen SM, Leinonen H, and Levonenn AL (2013) The Keap1-Nrf2 pathway: Mechanisms of activation and dysregulation in cancer. Redox Biology 1:45-49.

Karuppagounder V, Arumugam S, Thandavarayan RA, Pitchaimani V, Sreedhar R, Afrin R, Harima M, Suzuki H, Nomoto M, Miyashita S, Suzuki K, Nakamura M, and Watanabe K (2015) Modulation of HMGB1 translocation and RAGE/NFkappaB cascade by quercetin treatment mitigates atopic dermatitis in NC/Nga transgenic mice. Exp Dermatol 24:418423.

Kensler TW, Wakabayashi N, and Biswal S (2007) Cell survival responses to environmental stresses via the Keap1-Nrf2-ARE pathway. Annu Rev Pharmacol Toxicol 47:89-116.

Kim HJ, Barajas B, Wang M, and Nel AE (2008) Nrf2 activation by sulforaphane restores the agerelated decrease of $\mathrm{T}(\mathrm{H}) 1$ immunity: role of dendritic cells. J Allergy Clin Immunol 121:1255-1261 e1257.

Kourakis S, Timpani CA, Haan JBd, Gueven N, Fischer D, and Rybalka E (2020) Dimethyl Fumarate and Its Esters: A Drug with Broad Clinical Utility? Pharmaceuticals 13:1-15.

Kuo PC, Brown DA, Scofield BA, Yu IC, Chang FL, Wang PY, and Yen JH (2016) 3H-1,2-dithiole-3thione as a novel therapeutic agent for the treatment of experimental autoimmune encephalomyelitis. Brain Behav Immun 57:173-186.

Kuo PC, Weng WT, Scofield BA, Paraiso HC, Brown DA, Wang PY, Yu IC, and Yen JH (2020) Dimethyl itaconate, an itaconate derivative, exhibits immunomodulatory effects on neuroinflammation in experimental autoimmune encephalomyelitis. $J$ Neuroinflammation 17:138.

Larabee CM, Desai S, Agasing A, Georgescu C, Wren JD, Axtell RC, and Plafker SM (2016) Loss of Nrf2 exacerbates the visual deficits and optic neuritis elicited by experimental autoimmune encephalomyelitis. Mol Vis 22:1503-1513. 
Li CH, Sayeau K, and Ellis AK (2020) Air Pollution and Allergic Rhinitis: Role in Symptom Exacerbation and Strategies for Management. J Asthma Allergy 13:285-292.

Li J, Stein TD, and Johnson JA (2004a) Genetic dissection of systemic autoimmune disease in Nrf2-deficient mice. Physiol Genomics 18:261-272.

Li N, Alam J, Venkatesan MI, Eiguren-Fernandez A, Schmitz D, Di Stefano E, Slaughter N, Killeen E, Wang X, Huang A, Wang M, Miguel AH, Cho A, Sioutas C, and Nel AE (2004b) Nrf2 is a key transcription factor that regulates antioxidant defense in macrophages and epithelial cells: protecting against the proinflammatory and oxidizing effects of diesel exhaust chemicals. J Immunol 173:3467-3481.

Li N, Wang M, Barajas B, Sioutas C, Williams MA, and Nel AE (2013) Nrf2 Deficiency in Dendritic Cells Enhances the Adjuvant Effect of Ambient Ultrafine Particles on Allergic Sensitization. J Innate Immun 5:543-554.

Li R, Jia Z, and Zhu H (2019) Regulation of Nrf2 Signaling. React Oxyg Species (Apex) 8:312-322.

Li W, Khor TO, Xu C, Shen G, Jeong WS, Yu S, and Kong AN (2008a) Activation of Nrf2antioxidant signaling attenuates NFkappaB-inflammatory response and elicits apoptosis. Biochem Pharmacol 76:1485-1489.

Li YJ, Takizawa H, Azuma A, Kohyama T, Yamauchi Y, Takahashi S, Yamamoto M, Kawada T, Kudoh S, and Sugawara I (2008b) Disruption of Nrf2 enhances susceptibility to airway inflammatory responses induced by low-dose diesel exhaust particles in mice. Clin Immunol 128:366-373.

Li YJ, Takizawa H, Azuma A, Kohyama T, Yamauchi Y, Takahashi S, Yamamoto M, Kawada T, Kudoh S, and Sugawara I (2010) Nrf2 is closely related to allergic airway inflammatory responses induced by low-dose diesel exhaust particles in mice. Clin Immunol 137:234241.

Liu GH, Qu J, and Shen X (2008) NF-kappaB/p65 antagonizes Nrf2-ARE pathway by depriving CBP from Nrf2 and facilitating recruitment of HDAC3 to MafK. Biochim Biophys Acta 1783:713-727.

Lodovici M and Bigagli E (2011) Oxidative stress and air pollution exposure. J Toxicol 2011:487074.

London NR, Jr., Tharakan A, Lane AP, Biswal S, and Ramanathan M, Jr. (2017) Nuclear erythroid 2-related factor 2 activation inhibits house dust mite-induced sinonasal epithelial cell barrier dysfunction. Int Forum Allergy Rhinol 7:536-541.

Ma Q (2013) Role of nrf2 in oxidative stress and toxicity. Annu Rev Pharmacol Toxicol 53:401426.

Ma Q, Battelli L, and Hubbs AF (2006) Multiorgan autoimmune inflammation, enhanced lymphoproliferation, and impaired homeostasis of reactive oxygen species in mice lacking the antioxidant-activated transcription factor Nrf2. Am J Pathol 168:1960-1974.

McMahon M, Thomas N, Itoh K, Yamamoto M, and Hayes JD (2004) Redox-regulated turnover of Nrf2 is determined by at least two separate protein domains, the redox-sensitive Neh2 degron and the redox-insensitive Neh6 degron. J Biol Chem 279:31556-31567.

Miao W, Hu L, Scrivens PJ, and Batist G (2005) Transcriptional regulation of NF-E2 p45-related factor (NRF2) expression by the aryl hydrocarbon receptor-xenobiotic response element signaling pathway: direct cross-talk between phase I and II drug-metabolizing enzymes. J Biol Chem 280:20340-20348. 
Mohamed AF, El-Yamany MF, El-Batrawy FA, and Abdel-Aziz MT (2018) JNJ7777120 Ameliorates Inflammatory and Oxidative Manifestations in a Murine Model of Contact Hypersensitivity via Modulation of TLR and Nrf2 Signaling. Inflammation 41:378-389.

Mohan S and Gupta D (2018) Crosstalk of toll-like receptors signaling and Nrf2 pathway for regulation of inflammation. Biomed Pharmacother 108:1866-1878.

Moi P, Chan K, Asunis I, Cao A, and Kan YW (1994) Isolation of NF-E2-related factor 2 (Nrf2), a NF-E2-like basic leucine zipper transcriptional activator that binds to the tandem NFE2/AP1 repeat of the beta-globin locus control region. Proc Natl Acad Sci U S A 91:99269930.

Mussotter F, Tomm JM, El Ali Z, Pallardy M, Kerdine-Romer S, Gotz M, von Bergen M, Haase A, and Luch A (2016) Proteomics analysis of dendritic cell activation by contact allergens reveals possible biomarkers regulated by Nrf2. Toxicol Appl Pharmacol 313:170-179.

Nagashima R, Kosai H, Masuo M, Izumiyama K, Noshikawaji T, Morimoto M, Kumaki S, Miyazaki Y, Motohashi H, Yamamoto M, and Tanaka N (2019) Nrf2 Suppresses Allergic Lung Inflammation by Attenuating the Type 2 Innate Lymphoid Cell Response. J Immunol 202:1331-1339.

Nguyen T, Sherratt PJ, and Pickett CB (2003) Regulatory mechanisms controlling gene expression mediated by the antioxidant response element. Annu Rev Pharmacol Toxicol 43:233-260.

Ogawa T, Ishitsuka Y, Inoue S, Nakamura Y, Saito A, Okiyama N, Fujisawa Y, Furuta J, Watanabe $\mathrm{R}$, and Fujimoto M (2020a) Nuclear Factor Erythroid 2-Related Factor 2 (Nrf2) Regulates Epidermal Keratinization under Psoriatic Skin Inflammation. Am J Pathol 190:577-585.

Ogawa T, Ishitsuka Y, Nakamura Y, Kubota N, Saito A, Fujisawa Y, Watanabe R, Okiyama N, Suga $Y$, Roop DR, and Fujimoto M (2020b) NRF2 Augments Epidermal Antioxidant Defenses and Promotes Atopy. J Immunol 205:907-914.

Pardo M, Qiu X, Zimmermann R, and Rudich Y (2020) Particulate Matter Toxicity Is Nrf2 and Mitochondria Dependent: The Roles of Metals and Polycyclic Aromatic Hydrocarbons. Chem Res Toxicol 33:1110-1120.

Park G, Oh DS, Lee MG, Lee CE, and Kim YU (2016) 6-Shogaol, an active compound of ginger, alleviates allergic dermatitis-like skin lesions via cytokine inhibition by activating the Nrf2 pathway. Toxicol Appl Pharmacol 310:51-59.

Pawankar R, Mori S, Ozu C, and Kimura S (2011) Overview on the pathomechanisms of allergic rhinitis. Asia Pacific Allergy 1:157-157.

Rangasamy T, Guo J, Mitzner WA, Roman J, Singh A, Fryer AD, Yamamoto M, Kensler TW, Tuder RM, Georas SN, and Biswal S (2005) Disruption of Nrf2 enhances susceptibility to severe airway inflammation and asthma in mice. J Exp Med 202:47-59.

Rangasamy T, Williams MA, Bauer S, Trush MA, Emo J, Georas SN, and Biswal S (2010) Nuclear erythroid 2 p45-related factor 2 inhibits the maturation of murine dendritic cells by ragweed extract. Am J Respir Cell Mol Biol 43:276-285.

Robledinos-Anton N, Fernandez-Gines R, Manda G, and Cuadrado A (2019) Activators and Inhibitors of NRF2: A Review of Their Potential for Clinical Development. Oxid Med Cell Longev 2019:9372182.

Rockwell CE, Zhang M, Fields PE, and Klaassen CD (2012) Th2 skewing by activation of Nrf2 in CD4(+) T cells. J Immunol 188:1630-1637. 
Saha S, Buttari B, Panieri E, Profumo E, and Saso L (2020) An Overview of Nrf2 Signaling Pathway and Its Role in Inflammation. Molecules 2020, Vol 25, Page 5474 25:5474-5474.

Sakurai H, Morishima Y, Ishii Y, Yoshida K, Nakajima M, Tsunoda Y, Hayashi SY, Kiwamoto T, Matsuno Y, Kawaguchi M, Yamamoto M, and Hizawa N (2018) Sulforaphane ameliorates steroid insensitivity through an Nrf2-dependent pathway in cigarette smoke-exposed asthmatic mice. Free Radic Biol Med 129:473-485.

Satoh T and Lipton S (2017) Recent advances in understanding NRF2 as a druggable target: development of pro-electrophilic and non-covalent NRF2 activators to overcome systemic side effects of electrophilic drugs like dimethyl fumarate. F1000Res 6:2138.

Satta S, Mahmoud AM, Wilkinson FL, Yvonne Alexander M, and White SJ (2017) The Role of Nrf2 in Cardiovascular Function and Disease. Oxid Med Cell Longev 2017:9237263.

Seidel P and Roth M (2013) Anti-inflammatory dimethylfumarate: a potential new therapy for asthma? Mediators Inflamm 2013:875403.

Seumois G, Chavez L, Gerasimova A, Lienhard M, Omran N, Kalinke L, Vedanayagam M, Ganesan AP, Chawla A, Djukanovic R, Ansel KM, Peters B, Rao A, and Vijayanand P (2014) Epigenomic analysis of primary human T cells reveals enhancers associated with TH2 memory cell differentiation and asthma susceptibility. Nat Immunol 15:777-788.

Shen S, Li J, You H, Wu Z, Wu Y, Zhao Y, Zhu Y, Guo Q, Li X, Li R, Ma P, Yang X, and Chen M (2017) Oral exposure to diisodecyl phthalate aggravates allergic dermatitis by oxidative stress and enhancement of thymic stromal lymphopoietin. Food Chem Toxicol 99:60-69.

Shintani Y, Maruoka S, Gon Y, Koyama D, Yoshida A, Kozu Y, Kuroda K, Takeshita I, Tsuboi E, Soda K, and Hashimoto S (2015) Nuclear factor erythroid 2-related factor 2 (Nrf2) regulates airway epithelial barrier integrity. Allergol Int 64 Suppl:S54-63.

Shivdasani RA and Orkin SH (1995) Erythropoiesis and globin gene expression in mice lacking the transcription factor NF-E2. Proc Natl Acad Sci U S A 92:8690-8694.

Staurengo-Ferrari L, Badaro-Garcia S, Hohmann MSN, Manchope MF, Zaninelli TH, Casagrande $\mathrm{R}$, and Verri WA, Jr. (2018) Contribution of Nrf2 Modulation to the Mechanism of Action of Analgesic and Anti-inflammatory Drugs in Pre-clinical and Clinical Stages. Front Pharmacol 9:1536.

Sussan TE, Gajghate S, Chatterjee S, Mandke P, McCormick S, Sudini K, Kumar S, Breysse PN, Diette GB, Sidhaye VK, and Biswal S (2015) Nrf2 reduces allergic asthma in mice through enhanced airway epithelial cytoprotective function. Am J Physiol Lung Cell Mol Physiol 309:L27-36.

Takada-Takatori Y, Takeda Y, Imai R, Izumi Y, Akaike A, Tsuchida K, and Kume T (2019) Effects of $2^{\prime}-3^{\prime}$-dihydroxy-4' ,6' -dimethoxychalcone derived from green perilla on auricle thickness in chronic contact dermatitis model mice. Journal of Pharmacological Sciences 141:17-24.

Thimmulappa RK, Mai KH, Srisuma S, Kensler TW, Yamamoto M, and Biswal S (2002) Identification of Nrf2-regulated genes induced by the chemopreventive agent sulforaphane by oligonucleotide microarray. Cancer Res 62:5196-5203.

Thyssen JP, Linneberg A, Menne T, and Johansen JD (2007) The epidemiology of contact allergy in the general population--prevalence and main findings. Contact Dermatitis 57:287299. 
Tonelli C, Chio IIC, and Tuveson DA (2018) Transcriptional Regulation by Nrf2. Antioxidants and Redox Signaling 29:1727-1745.

Tong KI, Kobayashi A, Katsuoka F, and Yamamoto M (2006) Two-site substrate recognition model for the Keap1-Nrf2 system: a hinge and latch mechanism. Biol Chem 387:13111320.

Toyama T, Looney AP, Baker BM, Stawski L, Haines P, Simms R, Szymaniak AD, Varelas X, and Trojanowska M (2018) Therapeutic Targeting of TAZ and YAP by Dimethyl Fumarate in Systemic Sclerosis Fibrosis. J Invest Dermatol 138:78-88.

Van Nguyen T, Piao CH, Fan YJ, Shin DU, Kim SY, Song HJ, Song CH, Shin HS, and Chai OH (2020) Anti-allergic rhinitis activity of alpha-lipoic acid via balancing Th17/Treg expression and enhancing Nrf2/HO-1 pathway signaling. Sci Rep 10:12528.

Vandebriel RJ, Pennings JL, Baken KA, Pronk TE, Boorsma A, Gottschalk R, and Van Loveren H (2010) Keratinocyte gene expression profiles discriminate sensitizing and irritating compounds. Toxicol Sci 117:81-89.

Varshney J and Varshney H (2015) Allergic Rhinitis: an Overview. Indian J Otolaryngol Head Neck Surg 67:143-149.

Vocanson M, Hennino A, Rozieres A, Poyet G, and Nicolas JF (2009) Effector and regulatory mechanisms in allergic contact dermatitis. Allergy 64:1699-1714.

Wang C, Choi YH, Xian Z, Zheng M, Piao H, and Yan G (2018) Aloperine suppresses allergic airway inflammation through NF-kappaB, MAPK, and Nrf2/HO-1 signaling pathways in mice. Int Immunopharmacol 65:571-579.

Wardyn JD, Ponsford AH, and Sanderson CM (2015) Dissecting molecular cross-talk between Nrf2 and NF-kappaB response pathways. Biochem Soc Trans 43:621-626.

Weber FC, Nemeth T, Csepregi JZ, Dudeck A, Roers A, Ozsvari B, Oswald E, Puskas LG, Jakob T, Mocsai A, and Martin SF (2015) Neutrophils are required for both the sensitization and elicitation phase of contact hypersensitivity. J Exp Med 212:15-22.

Weidinger S, Beck LA, Bieber T, Kabashima K, and Irvine AD (2018) Atopic dermatitis. Nat Rev Dis Primers 4:1.

Williams LM, Lago BA, McArthur AG, Raphenya AR, Pray N, Saleem N, Salas S, Paulson K, Mangar RS, Liu Y, Vo AH, and Shavit JA (2016) The transcription factor, Nuclear factor, erythroid 2 ( $\mathrm{Nfe} 2$ ), is a regulator of the oxidative stress response during Danio rerio development. Aquat Toxicol 180:141-154.

Wruck CJ, Fragoulis A, Gurzynski A, Brandenburg LO, Kan YW, Chan K, Hassenpflug J, FreitagWolf S, Varoga D, Lippross S, and Pufe T (2011) Role of oxidative stress in rheumatoid arthritis: insights from the Nrf2-knockout mice. Ann Rheum Dis 70:844-850.

Wu W, Peng G, Yang F, Zhang Y, Mu Z, and Han X (2019) Sulforaphane has a therapeutic effect in an atopic dermatitis murine model and activates the Nrf2/HO1 axis. Mol Med Rep 20:1761-1771.

Yamamoto M, Kensler TW, and Motohashi H (2018) The KEAP1-NRF2 System: a Thiol-Based Sensor-Effector Apparatus for Maintaining Redox Homeostasis. Physiol Rev 98:11691203.

Yeager RL, Reisman SA, Aleksunes LM, and Klaassen CD (2009) Introducing the "TCDD-inducible AhR-Nrf2 gene battery". Toxicol Sci 111:238-246. 
Yu CH, Suh B, Shin I, Kim EH, Kim D, Shin YJ, Chang SY, Baek SH, Kim H, and Bae ON (2019) Inhibitory Effects of a Novel Chrysin-Derivative, CPD 6, on Acute and Chronic Skin Inflammation. Int J Mol Sci 20.

Zhao $\mathrm{K}$ and Wen LB (2018) DMF attenuates cisplatin-induced kidney injury via activating Nrf2 signaling pathway and inhibiting NF-kB signaling pathway. Eur Rev Med Pharmacol Sci 22:8924-8931. 


\section{Footnotes}

This work was supported by National Institute of Health grants [ES024966] and [ES030766].

Conflict of interest: The authors declare that they have no actual or perceived conflicts of interest with the contents of this article. 


\section{Figure legends}

Fig. 1. The role of Nrf2 in airway inflammation. Nrf2 can either contribute to or be protective against airway inflammation. Nrf2 has been shown to be protective in OVAinduced airway inflammation by promoting airway epithelial cell barrier function. In contrast, Nrf2 contributes to airway inflammation caused by PM2.5 through a mechanism that is thought it involve CYP2E1. 
Table 1: Studies focused on the role of Nrf2 in allergic airway and asthma

\begin{tabular}{|c|c|c|c|c|}
\hline Disease Model & $\begin{array}{l}\text { Environmental } \\
\text { factors/activators }\end{array}$ & $\begin{array}{l}\text { Genetic } \\
\text { Model }\end{array}$ & $\begin{array}{l}\text { Effect of } \\
\text { knockout/knockdown } \\
\text { (Nrf2 or Keap1) }\end{array}$ & References \\
\hline \multirow[t]{4}{*}{$\begin{array}{l}\text { OVA-induced allergic } \\
\text { airway } \\
\text { inflammation/asthma }\end{array}$} & & $\begin{array}{l}\text { CD1: ICR } \\
\text { WT \& Nrf2(-/-) }\end{array}$ & $\begin{array}{l}\uparrow \mathrm{AHR}, \uparrow \\
\text { inflammatory cell } \\
\text { infiltrate in lung, } \uparrow \\
\text { lipid peroxidation, } \uparrow \\
\text { IL-4, IL-13, } \uparrow \text { mucus } \\
\text { cell metaplasia }\end{array}$ & $\begin{array}{l}\text { (Rangasamy } \\
\text { et al., 2005) }\end{array}$ \\
\hline & Diesel & $\begin{array}{l}\text { C57BL/6 } \\
\text { WT \& Nrf2(-/-) }\end{array}$ & $\begin{array}{l}\uparrow \mathrm{AHR}, \uparrow \\
\text { inflammatory cells } \\
\text { infiltrate in lung, } \uparrow \mathrm{IL}- \\
5, \uparrow \text { mucus cell } \\
\text { hyperplasia }\end{array}$ & $\begin{array}{l}\text { (Li et al., } \\
2010)\end{array}$ \\
\hline & $\begin{array}{l}\text { ambient UFP } \\
(<0.18 \mu \mathrm{m})\end{array}$ & $\begin{array}{l}\text { BALB/c WT \& } \\
\text { Nrf2(-/-), DC } \\
\text { from WT \& } \\
\text { Nrf2(-/-) }\end{array}$ & $\begin{array}{l}\uparrow \text { Adjuvant effect of } \\
\text { intranasally instilled } \\
\text { UFP, } \uparrow \text { eosinophil } \\
\text { count and IL-13 in } \\
\text { BAL, V serum IgG1 }\end{array}$ & $\begin{array}{l}\text { (Li et al., } \\
\text { 2013) }\end{array}$ \\
\hline & & $\begin{array}{l}\text { Tam- } \\
\text { Keap1-- }^{-1}\end{array}$ & $\begin{array}{l}\downarrow \text { AHR, } \downarrow \\
\text { eosinophilic } \\
\text { inflammation, and } \downarrow \\
\text { IL-4 and IL-13 in } \\
\text { BAL }\end{array}$ & $\begin{array}{l}\text { (Sussan et } \\
\text { al., 2015) }\end{array}$ \\
\hline
\end{tabular}




\begin{tabular}{|c|c|c|c|c|}
\hline $\begin{array}{l}\text { Ragweed Extract- } \\
\text { induced asthma }\end{array}$ & & $\begin{array}{l}\text { BMDC and } \\
\text { lung DC from } \\
\text { WT Nrf2 (-/-) }\end{array}$ & $\begin{array}{l}\uparrow \mathrm{CD} 80, \mathrm{CD} 86, \text { and } \\
\mathrm{MHCI} \text { on DC, } \uparrow \text { IL-6 } \\
\text { and TNF- } \alpha \uparrow\end{array}$ & $\begin{array}{l}\text { (Rangasamy } \\
\text { et al., 2010) }\end{array}$ \\
\hline $\begin{array}{l}\mathrm{Cl}_{2} \text {-induced } \\
\text { inflammation and } \\
\text { airway } \\
\text { hyperresponsiveness }\end{array}$ & & $\begin{array}{l}\text { BALB/c } \\
\text { WT \& Nrf2(-/-) }\end{array}$ & $\begin{array}{l}\downarrow \text { mRNA for } \\
\text { antioxidant genes } \\
\text { (NQO-1 and GPX2) }\end{array}$ & $\begin{array}{l}\text { (Ano et al., } \\
2017 \text { ) }\end{array}$ \\
\hline $\begin{array}{l}\text { IL-33-induced } \\
\text { allergic lung } \\
\text { inflammation }\end{array}$ & $\begin{array}{l}\text { CDDO-Im, 15d- } \\
\text { PGJ }_{2}\end{array}$ & $\begin{array}{l}\text { C57BL/6 } \\
\text { WT \& Nrf2(-/-) }\end{array}$ & $\begin{array}{l}\text { Transient } \uparrow \text { in IL-33, } \\
\uparrow \text { ILC2 proliferation }\end{array}$ & $\begin{array}{l}\text { (Nagashima } \\
\text { et al., 2019) }\end{array}$ \\
\hline \multirow[t]{2}{*}{$\begin{array}{l}\text { PM2.5-induced } \\
\text { airway inflammation }\end{array}$} & & $\begin{array}{l}\text { C57BL/6 } \\
\text { WT \& Nrf2(-/-) }\end{array}$ & $\begin{array}{l}\downarrow \text { Inflammatory } \\
\text { infiltrate, } \downarrow \text { oxidative } \\
\text { stress, } \downarrow \text { lung injury, } \\
\downarrow \text { Cyp2E1 }\end{array}$ & $\begin{array}{l}\text { Ding et al., } \\
2021\end{array}$ \\
\hline & & $\begin{array}{l}\text { C57BL/6 } \\
\text { WT \& Nrf2(-/-) }\end{array}$ & $\begin{array}{l}\uparrow \text { Lung function, } \downarrow \\
\text { alveolar wall } \\
\text { thickening, } \downarrow \text { in low- } \\
\text { grade inflammation }\end{array}$ & $\begin{array}{l}\text { Jiang et al., } \\
2021\end{array}$ \\
\hline
\end{tabular}


Table 2: Studies focused on the role of Nrf2 in skin allergy

\begin{tabular}{|c|c|c|c|}
\hline Disease & Model & Effect of Nrf2-knockout & References \\
\hline Atopic Dermatitis & $\begin{array}{l}\text { BALB/c } \\
\text { WT \& Nrf2 (-/-) }\end{array}$ & $\begin{array}{l}\downarrow \text { Ear thickness; } \downarrow \\
\text { effector cell infiltration, } \downarrow \\
\text { type } 2 \text { cytokine, } \downarrow \text { IgE } \\
\text { response }\end{array}$ & (Wu et al., 2019) \\
\hline \multirow[t]{3}{*}{ Contact Dermatitis } & $\begin{array}{l}\text { Ex vivo: BMDC } \\
\text { Nrf2 (+/+) vs. (-/-) }\end{array}$ & $\begin{array}{l}\downarrow \text { Expression of } \\
\text { antioxidant genes }\end{array}$ & (Mussotter et al., 2016) \\
\hline & $\begin{array}{l}\text { C57/BL6 } \\
\text { WT \& Nrf2(-/-) }\end{array}$ & $\begin{array}{l}\uparrow \mathrm{PMN} \text { recruitment to skin } \\
\text { during sensitization phase }\end{array}$ & (Helou et al., 2019) \\
\hline & $\begin{array}{l}\text { C57/BL6 } \\
\text { WT \& Nrf2(-/-) }\end{array}$ & $\uparrow$ Ear thickness, & $\begin{array}{l}\text { (El Ali et al., 2013; } \\
\text { Helou et al., 2019) }\end{array}$ \\
\hline
\end{tabular}


Cytoprotection $\downarrow$

pithelial cell

barrier function $\downarrow$

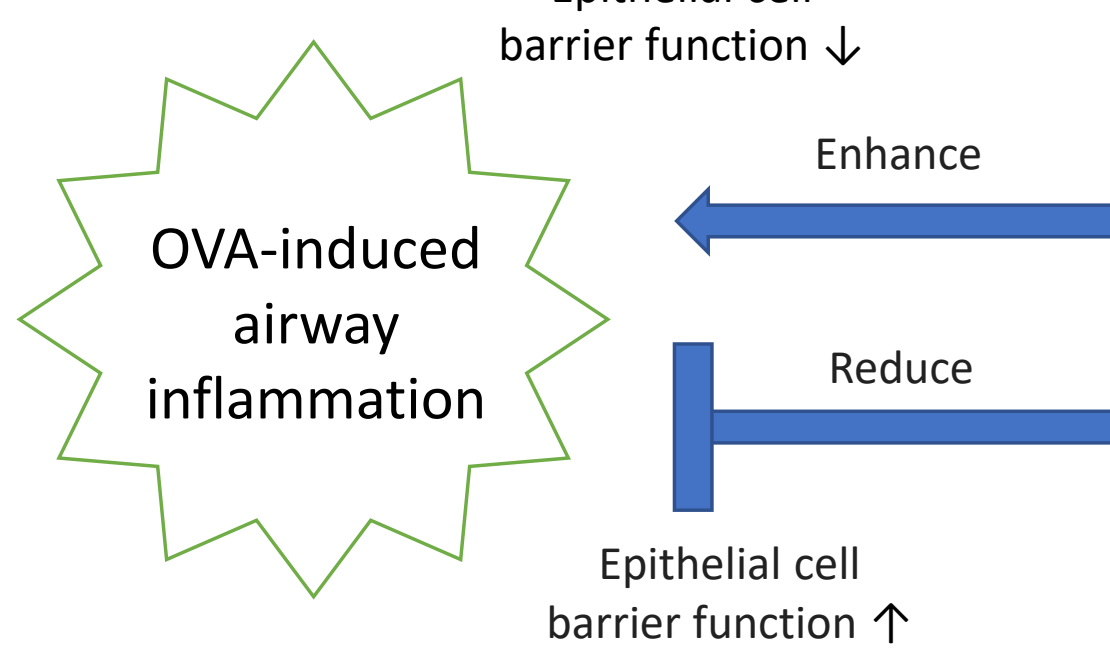

Nrf2

knockout

Oxidative S塻ess $\downarrow$

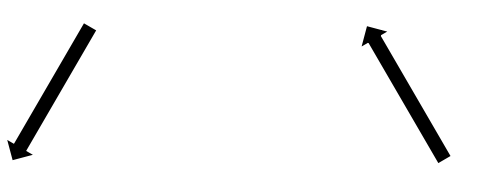

I

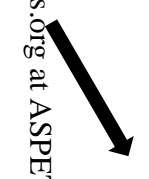

OCyp2E1 $\downarrow$

$(-)$ $\stackrel{\varrho}{\supset}$

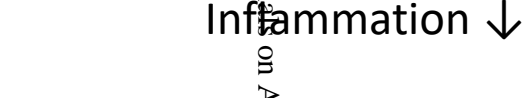

$-)$

Nrf2

(+)

Nrf2

activator

Cyp2E1个

Inflammation $\uparrow$

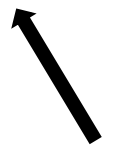

I

1

I

Cytoprotection $\uparrow$

Oxidative Stress $\uparrow$ 